\title{
POTENTIAL OF HEAT PIPE TECHNOLOGY IN NUCLEAR SEAWATER DESALINATION
}

\footnotetext{
Hussam Jouhara', Vladimir Anastasov², Ibrahim Khamis ${ }^{2}$

${ }^{1}$ School of Engineering and Design, Brunel University, Uxbridge, Middlesex, UB8 3PH, UK Tel: +44 1895 267656, Fax: +44 1895 256392, Email: hussam.jouhara@brunel.ac.uk

${ }^{2}$ International Atomic Energy Agency, Wagramer Strasse 5, P. O. Box 100, A-1400, Vienna, Austria, Tel: +43 1 260022822, Fax: +43 1260029598 E-mail: i.khamis@iaea.org
} 


\section{Abstract}

Heat pipe technology may play a decisive role in improving the overall economics, and public perception on nuclear desalination, specifically on seawater desalination. When coupled to the Low-Temperature Multi-Effect Distillation process, heat pipes could effectively harness most of the waste heat generated in various types of nuclear power reactors. Indeed, the potential application of heat pipes could be seen as a viable option to nuclear seawater desalination where the efficiency to harness waste heat might not only be enhanced to produce larger quantities of potable water, but also to reduce the environmental impact of nuclear desalination process. Furthermore, the use of heat pipes-based heat recovery systems in desalination plant may improve the overall thermodynamics of the desalination process, as well as help to ensure that the product water is free from any contamination which occur under normal process, thus preventing operational failure occurrences as this would add an extra loop preventing direct contact between radiation and the produced water. In this paper, a new concept for nuclear desalination system based on heat pipe technology is introduced and the anticipated reduction in the tritium level resulting from the use of heat pipe systems is discussed.

Keywords: Heat pipe, nuclear, seawater desalination

\section{Introduction}

Limited fresh water resources and an expanding world population, places high demand to the seawater desalination option. However, environmental concerns over the increasing concentration of green-house gases in the atmosphere, particularly carbon dioxide, make nuclear seawater desalination more favourable than conventional systems. Another option, which is expected to make nuclear desalination more viable, is the recovery of waste heat generated in nuclear power to produce fresh water, in parallel to electrical power. By coupling a nuclear reactor to a desalination plant, a more reliable, cost effective and safe desalination system is always a top priority. To enhance further such priority, new ideas are pursued, which are expected to eliminate leaks in heat exchangers, alleviate environmental impact, and prevent radioactive cross contamination to the product water [1].

Recent studies show that nuclear seawater desalination is achieved using one or more of the following three major desalination processes, namely: the Multistage Flash (MSF), Multi-Effect 
Distillation (MED) and the Reverse Osmosis (RO). The specific heat/electrical consumptions for MSF, MED and RO processes are 100/3, 50/2.5, and 0/4.5 $\left(\mathrm{kW}_{\text {th }} \cdot \mathrm{h} / \mathrm{m}^{3}\right) /\left(\mathrm{kW}_{\mathrm{e}} \cdot \mathrm{h} / \mathrm{m}^{3}\right)$, respectively [1].

An alternative and better economic option to produce desalted water is to harness the waste heat generated from the nuclear power reactor originally operating to produce either electricity or steam for other applications. In such a case, the waste heat available from the nuclear power plant will be looked at as the energy required for the desalination process, which was otherwise lost to the surrounding environment. This virtually free source of energy is available at almost ideal conditions for the Low Temperature MED (LT-MED) desalination process.

Waste heat, indeed, is generated in large quantities in various types of nuclear reactors. For example, the Pebble Bed Modular Reactor (PBMR), a high temperature gas-cooled-type reactor, is prone to produce up to $300 \mathrm{MW}_{\text {th }}$ of waste heat at about $67^{\circ} \mathrm{C}$, which is a suitable temperature for the MED desalination process. Other types of nuclear reactors such as the Pressurized Water Reactors (PWR), the Canadian CANDU reactors, and the Indian Pressurized Heavy Water Reactors (PHWR), dissipate almost two thirds of their net thermal power in the heat sink (typically nuclear reactors have an electrical efficiencies, of around $32 \%$ as average). In some specific cases, even high-power nuclear research reactors could produce sufficient waste heat to be considered as a source of energy for desalination [2]. In the case of research reactors, these can be used to produce the required high-quality distilled water from seawater to meet the demands of the demineralized water makeup requirement of the reactor itself [1;2]. If not utilized, such waste heat energy will be dissipated to the ultimate heat sink (i.e. sea, rivers or air).

Efficient heat exchangers are required to harness the waste heat from various potential sections of the nuclear plant to be used in the water desalting process. Such heat exchangers should meet the minimum safety requirements to prevent contamination among the various sections of the plant and to ensure an efficient heat transfer process, making effective use of the available energy in the desalting process. At present, tube and shell heat exchangers are generally being used for desalination purposes. This type of heat exchangers has many disadvantages (as will be discussed later). To address these disadvantages, the use of heat pipe technology in desalination heat exchanger systems used in various desalination sections will be introduced. 
As of the many advantages of the heat pipe technology (will be discussed later), its utilization is expected to affect not only the overall economics but also to enhance the public perception, in specific, of the nuclear seawater desalination at large as it offers an efficient method to harvest the waste heat, and better handling of brine before discharge. Heat pipes can be used to build heat exchangers to effectively harness most of the waste heat being generated in various types of nuclear power reactors. Such waste heat is viewed as a free source of energy to produce fresh water. Due to its low temperature, waste heat is useful only when the Low-Temperature MultiEffect Distillation (LT-MED) process is used. The application of heat pipes could be seen as a viable option to nuclear seawater desalination where the efficiency to harness waste heat might not only be enhanced to produce larger quantities of desalted potable water, but also to make nuclear desalination more environmentally friendly.

Heat pipes may also be used to improve conditioning of the brine before discharging to the environment. In general, brine disposal can be an environmental and economical issue in some areas. Furthermore, brine disposal should be studied and engineered to reduce the harmful effects to the environment. Thus, guaranteeing that sensitive fauna and flora species to local seawater salinity are protected.

In this paper, the potential of using heat pipe based systems in nuclear seawater desalination will be discussed. Advantages of applying such technology at specific stages of the desalinisation process will be highlighted.

\section{Application of heat pipes in nuclear desalination}

The application of heat pipe technology in nuclear desalination can be envisaged as a cost reduction strategy, a measure to reduce environmental impact if applied as a heat recovery system, and a measure to enhance safety and quality of product water if used as an auxiliary loop to prevent contamination.

Heat pipes are hermetically sealed tubes containing a working fluid in both the liquid and vapour phases and a wick to allow for the return of the condensed working fluid to the evaporator, Figure 1a. If the system permits, cheaper heat pipes (without wicks) can be utilised provided that the evaporator section is lower than the condenser section (at least by an angle of $5^{\circ}$ [3]) thus allowing the working fluid in liquid phase to return from the condenser to the evaporator by 
gravity, see Figure $1 \mathrm{~b}$. The selection of the heat pipe working fluid and its shell and wick material depends largely on their chemical compatibility and the heat pipe working temperature range, $[4 ; 5]$. The amount of heat that can be transported by these devices is normally several orders of magnitude greater than that transported by pure conduction through a solid metal [6-8].

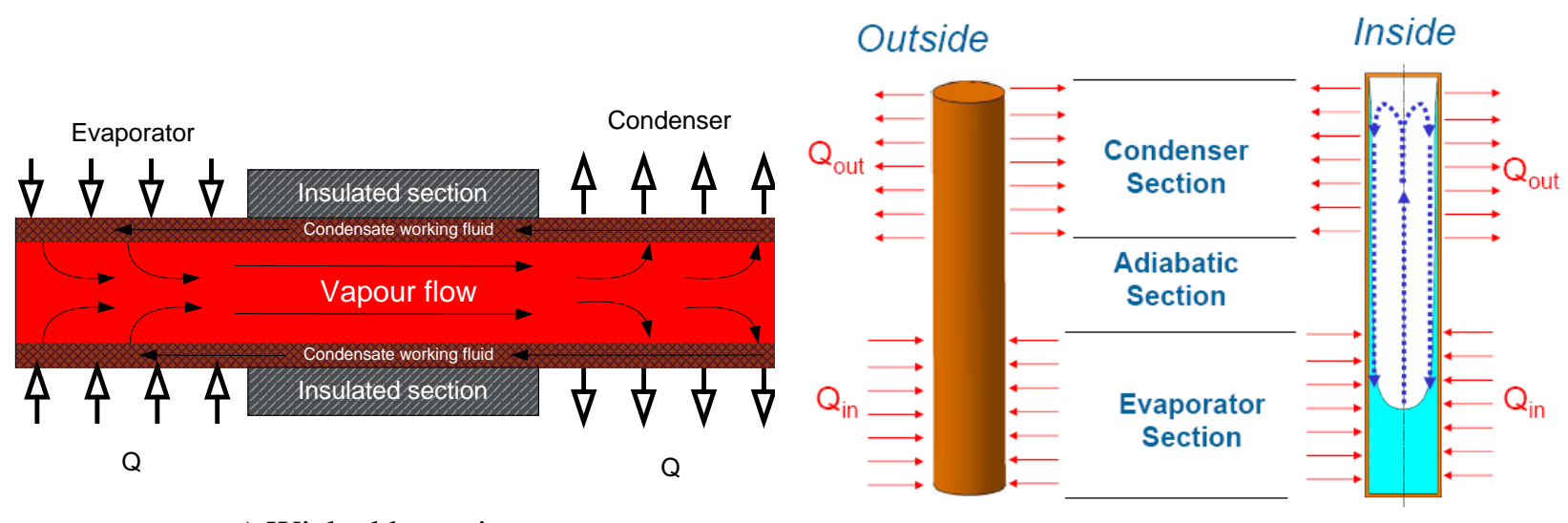

a) Wicked heat pipe

b) Wickless heat pipe (gravity assisted)

Figure 1. The concept of a heat pipe: a) wicked heat pipe, b) wickless heat pipe

Heat pipes can be used in bundles to create heat exchangers which are passive (no external power requirement) and contain no moving parts. They can be manufactured in a wide variety of sizes, and can be made compact and suitable for a wide range of thermal applications as of their high efficiency. Indeed, such advantages of heat-pipe-based heat exchangers resulted in their use in a wide range of applications. Many of these applications are related to space technology [9;10], thermal storage [11;12], harnessing of renewable energy [13-15] and in waste heat recovery of various processes [16;17].

Heat pipe based heat exchangers are likely to replace the conventional tube-shell heat exchangers in the evaporators and the condensers of the desalination plants. The benefits that heat pipe technology brings into the nuclear sea water desalination process are:

- A very efficient transfer of heat energy between two systems while the systems are physically separated. That eliminates the risk of mixing between the steam from the nuclear reactor and the seawater in the evaporator section and from the condensed fresh water and the brine in the condenser section of the desalination system. 
- It provides a much needed contingency plan to the process. In the heat pipe - based heat exchanger, the system will remain safely operational even if a number of heat pipes stopped functioning.

- Because of the high efficiency of the heat pipe heat exchangers, they will have much smaller size when compared to equivalent conventional heat exchangers.

- Major reduction in the fouling problem (the fouling problem is only an issue only on the external surfaces of the heat pipes).

- No need for any pumping power as the heat pipe is a passive heat transfer device.

\subsection{Application of heat pipes as heat exchangers}

Based on safety considerations, coupling between the nuclear power plant and the desalination processes requires the usage of several heat exchangers. Sometimes these are based on pressure reversal concept to prevent any radiation contamination between primary and secondary loops of the nuclear desalination system. For example, the MED plant is normally coupled to a nuclear reactor as by-pass to the main heat sink (river or sea). A typical configuration of backpressure coupling desalination to a nuclear power plant can be seen in Figure 2. Yet other turbine coupling scheme may include the coupling of a nuclear reactor to a thermal desalination plant using the backpressure turbine and a low-pressure turbine in parallel. In such cases, the conditions of the exhaust steam of the backpressure turbine (mass flow rate, temperature and pressure) are adjusted to the steam requirements of the thermal desalination plant.

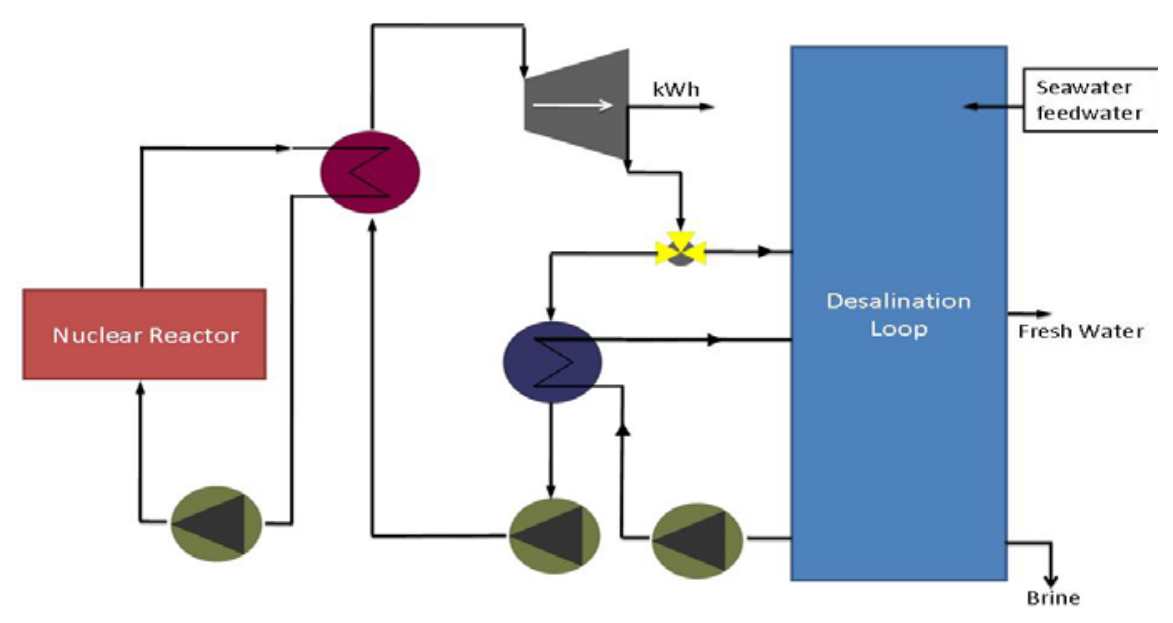


Figure 2. Typical coupling scheme of MED desalination plant to a nuclear reactor

Figure 3 presents a schematic diagram of a conventional Single effect desalination process [18] where the steam is used to evaporate the seawater and the feed liquid is used to condensate it.

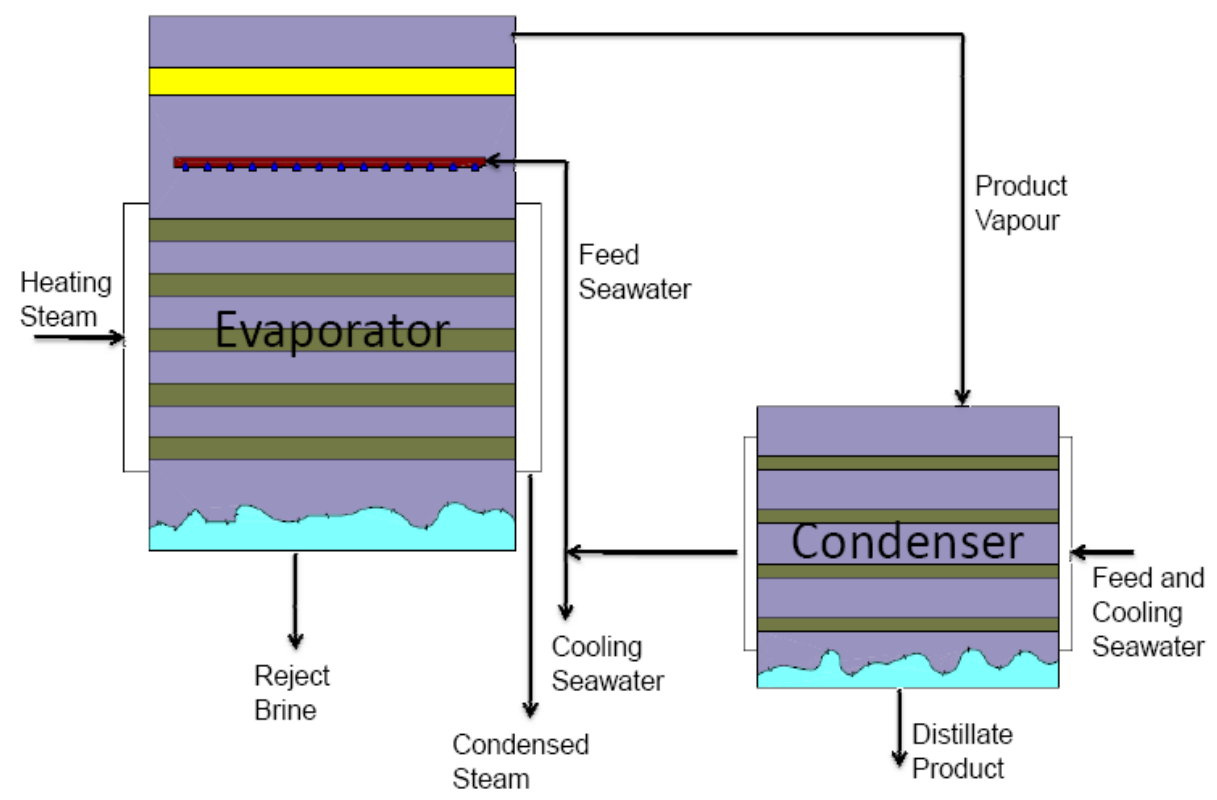

Figure 3. Conventional single effect desalination

There are a few concerns with the utilisation of such typical design (Figure 3) in the nuclear desalination process. These concerns are related to the integrity of the separating surfaces between the fluids. Examples of these concerns are as follows:

- In the evaporator section, if a leak happens in any of the steam tubes, of the shell-tube heat exchanger; it will lead to an interaction and mixing between the steam and the seawater (as a consequence, the whole system has to be shut down for maintenance and decontamination).

- The same scenario applies to the condenser section, where a leak will cause the fresh water produced to be contaminated by the feed seawater (the whole desalination process has to stop for maintenance.

- Fouling issues are of concerns (on the internal and external surfaces of the tubes) when using tube-shell heat exchanger, as this reduces the effectiveness of the heat exchange capacity of the system. 
By utilising heat pipe technology, the previous concerns will be addressed. A schematic of the proposed heat pipe-based system is illustrated in Figure 4. In the proposed system, heat pipes transmit the heat energy from the steam flow (from the nuclear plant) transferring it passively to the seawater feed chamber where it will be used to evaporate the seawater. The condensed steam from the steam chamber will then return to the nuclear plant. As illustrated in Figure 4, the steam chamber and the seawater feed are physically separated and heat pipes sections in the separation zone are usually well insulated (adiabatic sections). The same function of the heat pipe heat exchanger is illustrated for the waste heat recovery from the resulting brine (Figure 4 and illustrated further in Figure 5). The proposed heat pipe based system will have the following advantages:

- As the evaporator has two, physically separated chambers for the steam and the seawater flow; any leak in any of the chambers will not affect the other chamber thus eliminating the risk of contamination. In the extreme case of a leak in any of the heat pipes, the heat pipe shell will keep an active barrier between the steam-sea water in the evaporator zone and between the fresh water vapour/condensate and the feed seawater in the condenser zone. The same scenario can be said for the brine and the seawater feed for the brine system in Figure 4 and 5.

- It allows for a process contingency plan, which means that if a number of heat pipes would stop to function, the system would remain operational, at a reduced capacity, until the next scheduled maintenance stage.

- As the heat pipe has an extremely high effective thermal conductivity, by placing two temperature sensors on the hot and the cold sides of the heat pipe, the temperature difference will be an indication of the operational status, thus providing an easy detection of any faulty heat pipe.

- The ultra high effective thermal conductivity of the heat pipes means that the system will be totally passive (no need for pumping power for the heat energy transmission between the hot and the cold fluids).

- Fouling can only happens on the external surfaces of the tubes as the heat pipe is a sealed tube. 
The previous points and many others justify the use of heat pipe-based heat exchangers in the nuclear desalination systems. The heat pipe units shown in Figure 4 can be customised for the desired system capacity and conditions.

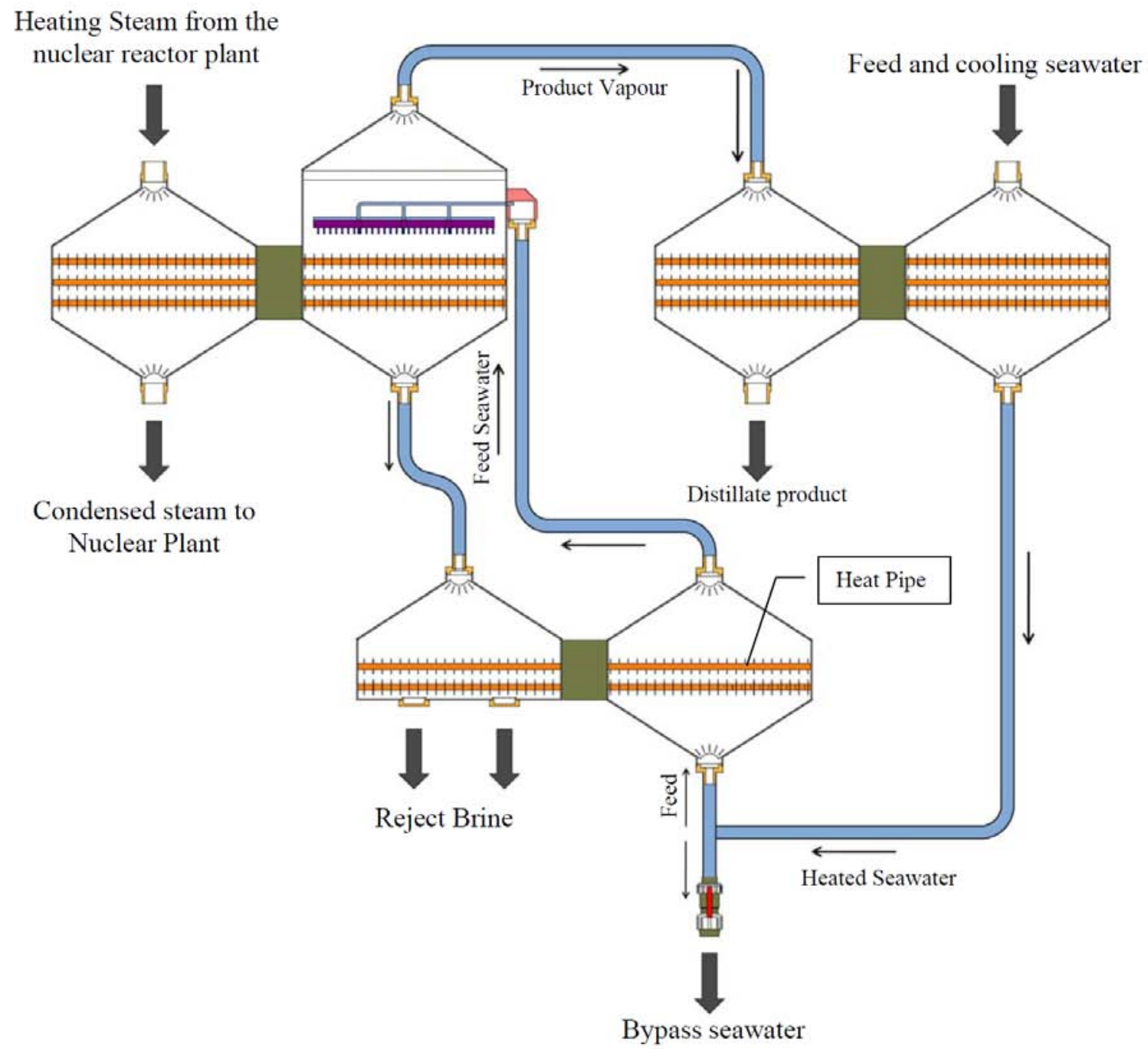

Figure 4. Heat Pipe-Based Single effect Desalination Plant 


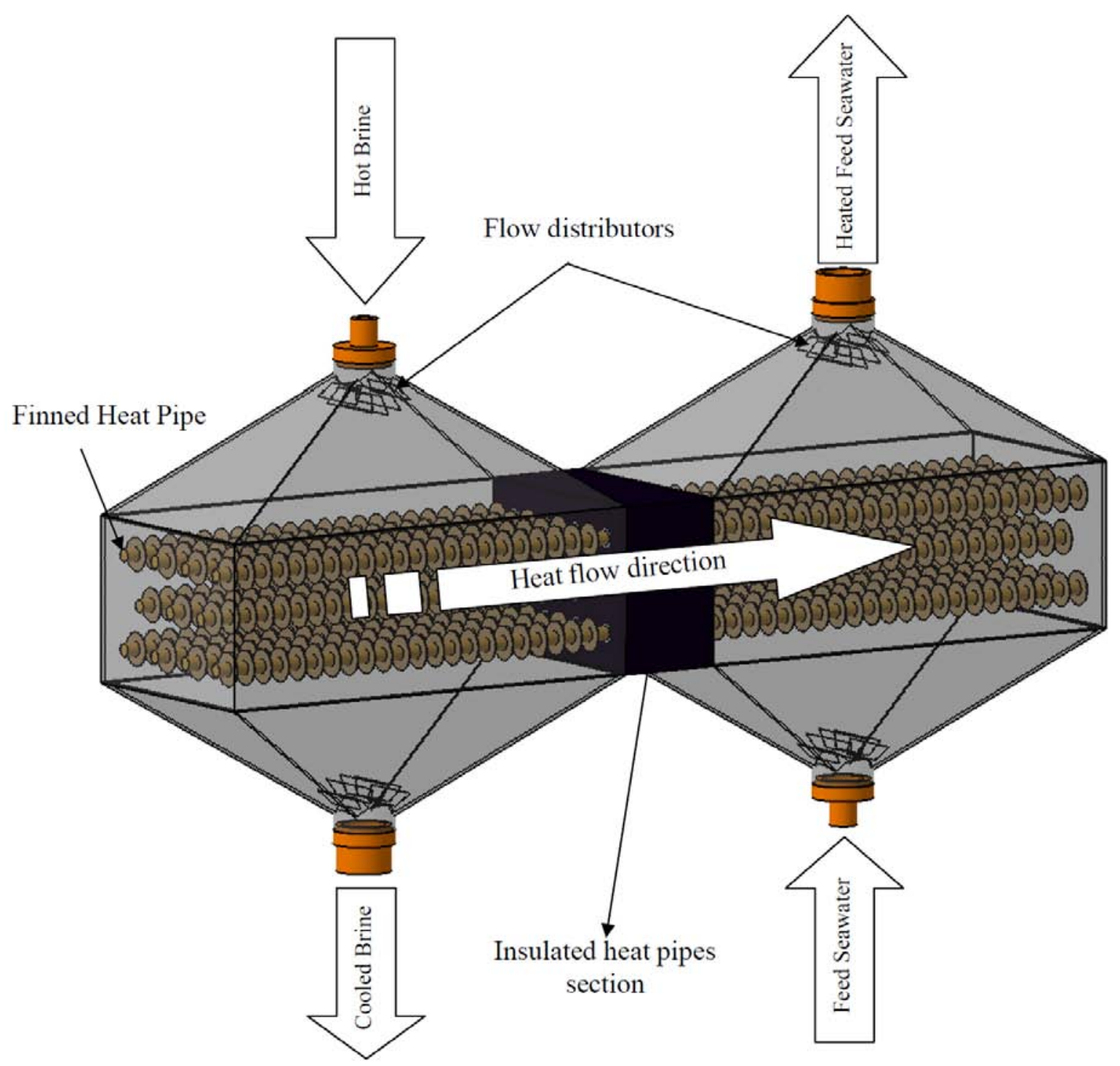

Figure 5. Typical heat pipe based heat exchanger to recover heat from the hot Brine to the seawater feed stream

\subsection{Application of heat pipes as a measure to alleviate environmental impacts}

Temperature is one of the most important single environmental factors, which affects the survival, growth and reproduction of aquatic organisms [19]. Distillation and desalination processes are typically associated with an increased brine temperature that affects the ultimate 
heat disposal system i.e. the receiving waters of sea or river. Higher brine temperature is responsible for higher corrosion rate of the desalination structure and subsequent adverse environmental impacts through increased discharge of toxic materials. Increasing seawater temperatures can potentially cause increased evaporation rates that may further elevate seawater salinity, and also causing adverse effects such as increased metabolic rate of the organisms and enhanced uptake of toxic pollutants, decreased levels of oxygen and nitrogen solubility in the seawater [20].

Illustrating this, a study [21] performed on Mediterranean seagrass Posidonia Oceanica, reported that for the same salinity levels, survival rates decreased with higher temperatures. Also, the abundance and diversity of plankton species is likely to decrease, resulting from lower oxygen and nitrogen levels in the seawater [18]. Such an impact on primary production may lead to overall habitat deterioration. Finally, temperature increases have the potential to kill marine organisms especially, benthic communities, such as corals - which are very sensitive to temperature changes. On the other hand, $1^{\circ} \mathrm{C}$ increment on discharge temperature is of no ecological impact [22]. Yet, combined effect of discharging of effluents from power-desalination plants, with increasing temperatures, contribute to an increase in the receiving seawater temperature which can often be observed several hundred meters away from the discharge point, depending on the technique used for discharging [23].

Therefore, the issue of thermal energy (i.e. heat) dissipation from nuclear desalination in the normal heat sinks (i.e. rivers, lakes, or oceans) is of great environmental concern. Removal of the excess heat from the brine will improve the protection of the aquatic ecosystems and at the same time allow for a more effective pre-heating of the feed water which reduces the energy required during the desalination process itself. The overall advantages of such heat recovery process will result in improved economics, offsetting the high cost and high energy consumption of the current process.

\subsection{Application of heat pipes as an auxiliary loop to prevent contamination}

Nuclear desalination requires specific and stringent safety measures to ensure that public health will not be at risk. These measures are designed to provide product safety and prevent radioactive contamination. Such contamination may occur due to diffusion of radio nuclides through physical barriers separating the nuclear and desalination loops. Far more probable and, due to the higher 
amount of radioactive release; more hazardous pathway is a possible leakage from the nuclear to the desalination loop. Irradiation corrosion and other types of corrosion of the reactor structure present a very real problem, because they can lead or material cracking and subsequent leakage [24].

To prevent the above risks, an intermediate loop was introduced between the nuclear and the desalination loop [25]. This intermediate loop must have a higher pressure than the nuclear one in order to ensure that should a leak occurs it will be directed from the intermediate to the nuclear side, not the other way around. Search for small ruptures though, is very difficult, so it is important always to maintain the higher intermediate pressure. The intermediate loop includes an additional heat exchanger towards the desalination loop, allowing for another physical barrier that should prevent radionuclide contamination of the desalination loop. This procedure is similar to the radiation safety principles applied to the schemes of using nuclear energy for district heating.

Tritium is the primary concern from the radiation product safety aspect. It is a radioactive hydrogen isotope which is highly penetrative and able to oxidize forming tritiated water, effectively following the same pathways as natural water. Depending on the reactor type, titrium is observed as a result of nuclear reactions in the fuel, coolant or moderator (see Table 1.). Most of the tritium is transported close to the desalination loop with the coolant. Unlike other, heavier radio nuclides, tritium cannot be removed by the RO membranes. Hence, an intermediate loop between the reactor and the desalination plant is designed to prevent tritium contamination of the desalination water [26].

Table 1. Typical tritium production per reactor type and source (GBq/GWe/year)

\begin{tabular}{lcccc}
\hline & Fuel & Coolant & Moderator & Total \\
\hline LWR-PWR & $5.18 \times 10^{5}$ & $3.70 \times 10^{4}$ & N/A & $5.55 \times 10^{5}$ \\
\hline LWR-BWR & $5.18 \times 10^{5}$ & Low & N/A & $5.18 \times 10^{5}$ \\
\hline HWR & $5.18 \times 10^{5}$ & $1.85 \times 10^{6}$ & $5.18 \times 10^{7}$ & $5.42 \times 10^{7}$ \\
\hline GCR & $5.18 \times 10^{5}$ & Low & $(0-1.85) \times 10^{5}$ & $(5.18-7.03) \times 10^{5}$ \\
\hline GCR-HTGR & $5.18 \times 10^{5}$ & $1.85 \times 10^{5}$ & $(0.18-7.40) \times 10^{4}$ & $(5.2-5.9) \times 10^{5}$ \\
\hline FBR & $7.40 \times 10^{5}$ & $7.40 \times 10^{4}$ & N/A & $8.14 \times 10^{5}$ \\
\hline
\end{tabular}

N/A: Data not available

However, there will always be a certain amount of tritium in the desalination loop, mainly due to diffusion of gaseous tritium through physical barriers. This cannot be totally prevented, although 
the diffusion rate will differ for different materials. It is important that the quantity of titrium diffused does not compromise the compliance with a set of health and safety protection limits*. Diffusion of gaseous tritium cannot be completely prevented by using physical barriers; however a large part of the formed tritium is in the form of tritiated water [27]. The latter is similar to natural water and cannot permeate through metallic barriers, making an intermediate loop with higher pressure a sufficient and effective radiation protection. The experience so far confirms this $[27 ; 28]$.

As discussed above, heat pipe heat exchangers offer many additional advantages for product water safety in nuclear desalination. For example, having a higher thermal efficiency, such systems require a reduced heat transfer surface potentially reducing tritium penetration. The tritium transfer rate $\mathrm{Q}_{\mathrm{tr}}$ to the next circuit is calculated with the following formula [29]:

$$
Q_{t r}=C_{h e} \times J_{h e} \times S_{h e} \times G_{h e}
$$

Where: $\mathrm{C}_{\text {he }}, \mathrm{J}_{\text {he }}, \mathrm{S}_{\text {he }}$ and $\mathrm{G}_{\text {he }}$ would represent, respectively, the concentration of tritium in the nuclear loop, the permeation flux (see Figure 6) of the heat pipe material, the combined surface of the heat pipes and the flow rate of the heat pipe system [30]. Assuming that the flow, the tritium concentration and the material of the heat exchanger and the heat pipe system are the same, it can be seen that a reduction in the heat exchanging surface will be followed by a proportional reduction in tritium migration in the desalination loop.

In addition, heat pipes can provide higher operational safety. Leaks can be detected and located, while a physical barrier to the desalination loop is still provided. Furthermore, heat pipe systems offer system design simplicity, hence, eliminating the need for an intermediate loop, or a second heat exchanger and/or a pump which would be needed to provide higher intermediate pressure. In such set up, any operational and maintenance costs associated with the intermediate loop are avoided. In addition, the safety factor is still maintained at the necessary level preventing meaningful tritium migration into the desalination loop. In summary, the intermediate loop may be substituted with heat pipe systems.

\footnotetext{
${ }^{*}$ Such as the ones on drinking water quality regarding tritium from WHO $(10,000 \mathrm{~Bq} / \mathrm{l})$ or US EPA (740 Bq/l)
} 
As a result, although tritium migration to the desalination loop will not be completely prevented due to the diffusion of gaseous tritium, one can still expect that heat pipes may prove as one of the effective tools for applying the ALARA principle on radiation safety in nuclear desalination.

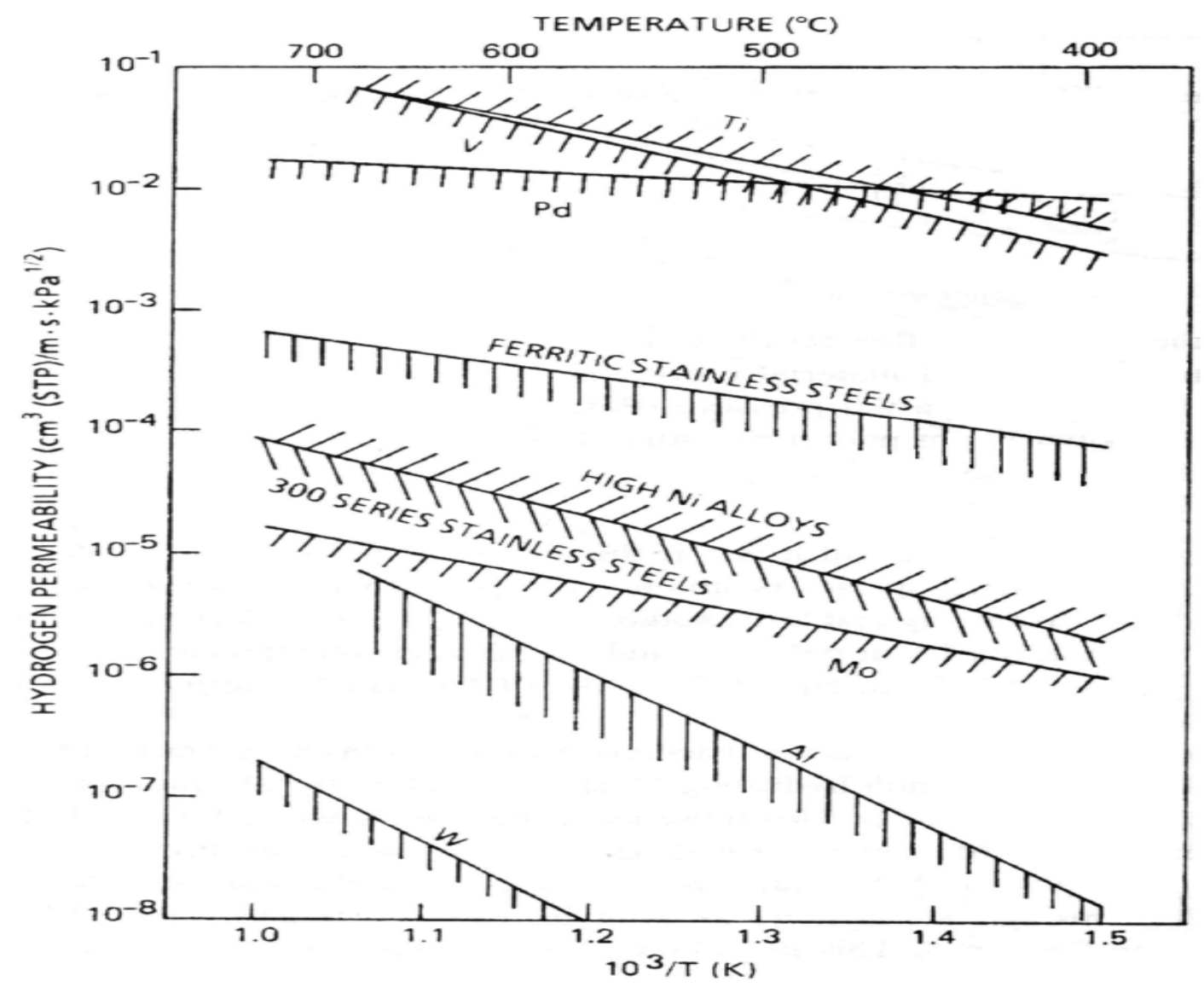

Figure 6. Hydrogen permeability as a function of temperature for selected metals and alloys

Furthermore, implementation of such technology may present additional benefits for easier and more constant regulatory compliance concerning radionuclide contamination of the desalination loop, which will certainly reflect positively on the public confidence and in the product quality.

\section{Conclusion}

Heat pipes are likely to play an important role in making nuclear seawater desalination more economical and efficient. Heat pipes show potential for reducing environmental impacts of nuclear desalination plants as they improve the overall thermodynamics of the desalination process. Additionally, the use of heat pipes is likely to help ensuring that the product water is free from any contamination which may occur under normal processes, thus preventing operational 
failure occurrences as this would add an extra loop preventing direct contact between radiation and the produced water. Of course, tritium diffusion cannot be totally prevented, but tritiated fluid leaks are likely to be significantly reduced. At the same time, application of heat pipes instead of the standard intermediate loop may reduce the capital, operating and maintenance costs whilst maintaining safety levels.

\section{References}

[1]. International Atomic Energy Agency, Economics of Nuclear Desalination: New Developments and Site Specific Studies, IAEA-TECDOC-1561, Vienna, 2007.

[2]. International Atomic Energy Agency, Status of Nuclear Desalination in IAEA Member States, IAEATECDOC-1524, Vienna, 2007.

[3]. A. Faghri, (1 $1^{\text {st }}$ Ed.), Heat Pipe Science and Technology, Taylor \& Francis, 1995.

[4]. H. Jouhara. A.J. Robinson, An experimental study of small diameter wickless heat pipes operating in the temperature range $200^{\circ} \mathrm{C}$ to $450^{\circ} \mathrm{C}$, Heat Transfer Engineering, 30 (13), (2009) 1-8.

[5]. H. Jouhara, O. Martinet, A.J. Robinson, Experimental Study of Small Diameter Thermosyphons Charged with Water, FC-84, FC-77 \& FC-3283, The proceeding of the $5^{\text {th }}$ European Thermal-Sciences Conference (Eurotherm), Eindhoven, The Netherlands, (2008).

[6]. S.H. Noie, Heat transfer characteristics of a two-phase closed thermosyphon, Applied Thermal Engineering, 25(4) (2005) 495-506.

[7]. P. Dunn and D. Reay, ( $4^{\text {th }}$ Ed.), Heat Pipes, Pergamon, 1994.

[8]. D. Reay and P. A. Kew, (5 ${ }^{\text {th }}$ Ed.) Heat Pipes, Elsevier, 2006.

[9]. C.J. Savage, Heat pipes and vapour chambers for satellite thermal balance. RAE Tech. Report 69125, June 1969.

[10]. T.D. Swanson. G.C. Birur. NASA thermal control technologies for robotic spacecraft. Applied Thermal Engineering, 23, (2003) 1055-1065.

[11]. A. Caruso, et al. Heat pipe heat storage performance. Heat Recovery Systems CHP, 9(5) (1989) 407-410.

[12]. B. Zalba. J.M. Marin. L.F. Cabeza. H. Mehling, Review on thermal energy storage with phase change: materials, heat transfer analysis and applications. Applied Thermal Engineering, 23 (2003) 251-283.

[13]. Sodha et al. Solar Passive Building: Science and Design. Pergamon, Oxford, 1986.

[14]. E. Mathioulakis. V. Belessiotis, A new Heat-pipe Type Solar Domestic Hot Water System, Solar Energy, 72(1), (2002) 13-20.

[15]. Q.P. Sun. X.H. Chen. J. F. Chen, The Development and Application of Solar Energy Heatpipe, Energy Technology, 23 (3), (2002) 110-112. 
[16]. L.L. Vasiliev, Heat pipe research and development in the USSR. Heat Recovery Systems. CHP, 9 (4), (1989) 313-333.

[17]. H. Jouhara, Economic Assessment of the Benefits of Wraparound Heat Pipes in Ventilation Processes for Hot and Humid Climates, International Journal of Low Carbon Technology, 4 (1), (2009) 52-60.

[18]. T. Hisham El-Dessouky and M. Hisham Ettouney, ( $1^{\text {st }}$ Ed.), Fundamentals of Seawater Desalination, Elsevier Sciences, 2002.

[19]. O. Kinne, "Marine Ecology" Environmental Factors Part I, 1, Wiley, (1970) 321-363.

[20]. R. Miri. A. Chouikhi, Ecotoxicological marine impacts from seawater desalination plants, Desalination, 182, (2005) 403-410.

[21]. J.L. Sanchez-Lizaso. J. Romero. J. Ruiz. E. Gacia. J.L. Buceta. O. Invers. Y. Fernandez Torquemada. J. Mas. A. Ruiz-Mateo. M. Manzanera, Salinity tolerance of the Mediterranean seagrass Posidonia Oceanica: recommendations to minimize the impact of brine discharges from desalination plants, Desalination, 221, (2008) 602-607.

[22]. T. Hoepner, A procedure for environmental impact assessment (EIA) for seawater desalination plants, Desalination, 124, (1999) 1-12.

[23]. I. Alameddine. M. El-Fadel, Brine discharge from desalination plants: a modelling approach to an optimized outfall design", Desalination, 214, (2007) 241-260.

[24]. G. Bellanger, Corrosion induced by low-energy radionuclides, Elsevier. i,524, 2004.

[25]. International Atomic Energy Agency, Nuclear heat applications: design aspects and operating experience, IAEA, i,373, 1998.

[26]. International Atomic Energy Agency, Safety aspects of nuclear plants coupled with seawater desalination units, IAEA, i 82, 2001.

[27]. C.C. Liu. J.H. Chao, C.C. Lin, Tritium release from nuclear power plants in Taiwan, Health Phys. 84(3), (2003) 361-367.

[28]. Dr S. Prabhakar, BARC, Mumbai. Pers. comm.

[29]. E.D. Muralev, Tritium migration in nuclear desalination plants, International Journal of Nuclear Desalination 1(1), (2003) 104-115, 2003.

[30]. International Atomic Energy Agency, Safe Handling of Tritium. Review of Data and Experience, IAEA-TRS-324, Vienna, 1991. 